\title{
Prevalence of Abnormal Lipid and Blood Pressure Values Among an Ethnically Diverse Population of Eighth-Grade Adolescents and Screening Implications
}

\author{
Russell Jago, $\mathrm{PhD}^{\mathrm{a}}$, Joanne S. Harrell, $\mathrm{PhD}^{\mathrm{b}}$, Robert G. McMurray, $\mathrm{PhD}^{\mathrm{C}}$, Sharon Edelstein, \\ $\mathrm{ScM}^{\mathrm{d}}$, Laure El Ghormli, MSc ${ }^{\mathrm{d}}$, and Stanley Bassin, EdD ${ }^{\mathrm{e}}$

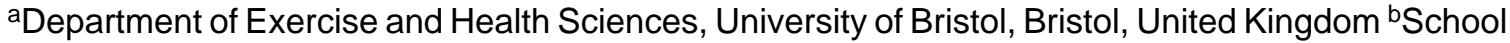 \\ of Nursing, University of North Carolina, Chapel Hill, North Carolina 'Department of Exercise and \\ Sport Science, University of North Carolina, Chapel Hill, North Carolina ${ }^{\mathrm{d}}$ George Washington \\ University Biostatistics Center, Rockville, Maryland ${ }^{\circ}$ Division of Cardiology, Preventive Cardiology \\ Program, University of California, Irvine, California
}

\begin{abstract}
OBJECTIVES-Our goal was to report the prevalence of elevated blood pressure and lipid levels among eighth-grade adolescents from 3 US locations and differences by gender, ethnicity, and overweight percentile group.

METHODS—Fasting blood samples and blood pressure levels were obtained from 1717 eighthgrade students from 12 predominantly minority schools in 3 states (Texas, California, and North Carolina) during spring 2003. Age, gender, ethnicity, weight, and height were ascertained and BMI calculated. The presence of abnormal total cholesterol, high-density lipoprotein cholesterol, lowdensity lipoprotein cholesterol and triglycerides, prehypertension, hypertension, at risk for overweight, and overweight were calculated and compared with the findings of previous youth studies. We examined whether prevalence differed by gender, ethnicity, or BMI group.
\end{abstract}

RESULTS-A total of $23.9 \%$ of participants had high blood pressure, $16.7 \%$ had borderline total cholesterol, $4.0 \%$ had high total cholesterol, $10.5 \%$ had borderline low-density lipoprotein cholesterol, 3.9\% had high low-density lipoprotein cholesterol, 13.3\% had low high-density lipoprotein cholesterol, and $17.2 \%$ had high triglycerides. A total of $19.8 \%$ of participants were at risk of overweight (BMI $\geq 85$ th percentile, $<95$ th percentile) and $29 \%$ were overweight (BMI $\geq 95$ th percentile). The prevalence of risk factors was associated $(P<.05)$ with the overweight group and differed by age and gender.

CONCLUSIONS-Prevalence of elevated blood pressure was higher in this sample than in previous national surveys in which subjects were less overweight. Associations between overweight and both elevated lipid and blood pressure levels suggest that adolescents overweight or at risk for overweight should be screened for elevated blood pressure and lipid levels.

\section{Keywords}

hypertension; cholesterol; African American; Hispanic 
ELEVATED Lipid $^{1}$ and blood pressure ${ }^{2}$ levels have been associated with an increased risk of cardiovascular disease and track from childhood to adulthood ${ }^{3-6}$ suggesting that the presence of elevated lipid or cholesterol levels during adolescence increases the risk of adult disease. Lipid levels and blood pressure levels have also been reported to vary by ethnicity,${ }^{7-10}$ gender, 7,9 and Tanner stage ${ }^{11,12}$ among children and adolescents.

In the Bogalusa Heart Study (1984-1994), 11.4\% of 11- to 17-year-olds were overweight (Quetelet index), 9\% had high total cholesterol (TC) levels ( $>200 \mathrm{mg} / \mathrm{dL}), 8 \% \mathrm{had}$ high $(>130$ $\mathrm{mg} / \mathrm{dL}$ ) low-density lipoprotein cholesterol (LDL-C), and $11 \%$ had low ( $<35 \mathrm{mg} / \mathrm{dL}$ ) highdensity lipoprotein cholesterol (HDL-C). ${ }^{13}$ Recent data from the National Health and Nutrition Examination Survey (NHANES) 1999-2000 showed that the prevalence of high triglycerides and low HDL-C remained virtually unchanged since NHANES III (1998-1994) among 12- to 19-year-olds at $23.2 \%$ and $23.4 \% .{ }^{14}$ However, the prevalence of elevated blood pressure among 12- to 19-year-olds had increased to $8.0 \%$ among all participants, $7.5 \%$ among white children, $11.3 \%$ among Mexican American children, and $12.7 \%$ among black children. The prevalence of overweight has been increasing among US adolescents. ${ }^{15}$ Overweight has been associated with dyslipidemia ${ }^{13,16}$ and increased blood pressure ${ }^{13,17,18}$ among both children and adolescents. As the prevalence of overweight has increased since NHANES 1999-2000 (from $15.0 \%$ in $1999-2000$ to $16.5 \%$ in 2001-2002), ${ }^{19}$ there is a need to report the prevalence of cardiovascular risks among adolescents and particularly minority adolescents during the current obesity epidemic.

This study reports the prevalence of elevated lipid and blood pressure levels among eighthgrade adolescents sampled from 3 ethnically diverse locations in the United States overall and according to ethnic group, overweight status, and gender during the spring of 2003.

\section{METHODS}

Data were collected as part of a pilot feasibility study conducted by the Studies to Treat or Prevent Pediatric Type 2 Diabetes (STOPP-T2D) Prevention Study Group, a National Institute of Diabetes Digestive and Kidney Disease multisite study designed to reduce the prevalence of type 2 diabetes mellitus among middle school children. At the time of data collection, the study was comprised of 3 field centers in Texas (Baylor College of Medicine, Houston, TX), California (University of California Irvine, Irvine, California), and North Carolina (University of North Carolina, Chapel Hill, NC), and a coordinating center (George Washington University Biostatistics Center, Rockville, MD).

\section{Inclusionary Criteria and Recruitment}

Participants were recruited from 12 schools, 4 schools at each of the 3 field centers. To participate in the study, at least $50 \%$ of the students enrolled at the school were required to be from an ethnic minority known to be at increased risk for type 2 diabetes mellitus (black, Native American, or Hispanic). Schools were also required to have at least $50 \%$ of their students eligible for free or reduced-price school lunch. Because participants were required to undertake an oral glucose tolerance test to determine the prevalence of type 2 diabetes (results reported elsewhere), consented students were required to be free from a current diagnosis of either type 1 or type 2 diabetes. With this exception, all eighth-grade students in the study schools who provided written parental informed consent and informed assent were eligible to participate in the study. Social marketing campaigns that included diabetes information sheets, student, teacher, and parent information sessions were implemented in each school to recruit students. Consent and assent were sought for a health screening that included medical history, pubertal development, blood pressure, and the provision of a fasting blood sample. Participants received $\$ 50$ and a free breakfast for participating in the study. The Baylor College of Medicine, 
University of California, Irvine, and University of North Carolina institutional review boards approved this study.

\section{Procedures}

Participant ethnicity was obtained by student self-report. Height was measured to the nearest $0.1 \mathrm{~cm}$ on a stadiometer (PE-AIM-101; Perspective Enterprises, Kalamazoo, MI) with the participants shoeless and the head in the Frankfort plane. Body mass was measured to the nearest $0.1 \mathrm{~kg}$ using a precalibrated electronic scale (SECA Alpha 882; Vogel and Halke, Hamburg, Germany). Research assistants who were within $90 \%$ agreement with a criterion observer during a prestudy training and certification procedure recorded all measurements. Body mass index (BMI) was then calculated $\left(\mathrm{kg} / \mathrm{m}^{2}\right)$. Participants' BMI percentile was then calculated using Centers for Disease Control and Prevention (CDC) age- and gender-specific percentiles ${ }^{20}$ and participants were grouped as normal weight (BMI $<85$ th percentile), at risk of becoming overweight ( 85 th $\geq$ BMI $<95$ th percentile), and overweight (BMI $\geq 95$ th percentile).

Pubertal development was measured by using the Pubertal Development Scale (PDS). ${ }^{21}$ The PDS has a 5-item subscale for each gender. Items were coded on a 4-level ordinal response and the results summed across the 5 items to produce a 5-level Tanner score. The PDS has been shown to have good associations with physician ratings of Tanner stage. ${ }^{21}$

Blood pressure was recorded 3 times by trained research assistants using an automated blood pressure monitor (Omron HEM-907; Vernon Hills, IL). The initial value was recorded after the participant had been seated quietly for 5 minutes with each subsequent value recorded 1 minute after the preceding recording. An appropriate-sized cuff was used for all participants. An adult automated blood pressure monitor (DinaMap Procare 100; GE, Tampa, FL) was used for participants whose upper arm circumference exceeded $42 \mathrm{~cm}$. The mean of the second and third recordings were used in all subsequent analyses. Blood pressure percentiles were determined using the National Heart Lung and Blood Institute guidelines and adjusted for age, gender, and height percentile ${ }^{22}$ with prehypertension being classified as either systolic or diastolic blood pressure between the 90th and 95th percentiles, and hypertension classified as systolic or diastolic blood pressure above the 95 th percentile. A third variable, any high blood pressure (HBP), was also created and classified as either systolic or diastolic blood pressure above the 90th percentile. Because participants could have a systolic blood pressure level that was prehypertensive and a diastolic blood pressure level that was hypertensive (or vice versa), participants with both a prehypertensive and hypertensive blood pressure level were counted only once.

Participants were asked at the beginning of the blood screening when they last ate and whether they were taking lipid-lowering or hypertensive medications. Participants who reported eating after midnight were considered nonfasting and asked to return another day. No participant reported taking lipid-lowering or antihypertension medications. Experienced pediatric phlebotomists obtained fasting blood samples and placed at least $2.0 \mathrm{~mL}$ of plasma in an EDTA tube; the tube was frozen and sent to the central laboratory at the University of Washington. Measurements of TC in plasma, cholesterol in the lipoprotein fractions, and triglycerides were performed enzymatically using a Hitachi 917 autoanalyzer and methods standardized to the CDC reference methods using standard laboratory procedures. ${ }^{23-26}$ Quality control procedures (BCL-Low, BCL-High [Biocell Laboratories]) were performed at the beginning and end of each run. The interassay coefficients of variation are consistently $<1.5 \%$ for TC and triglycerides and $<2 \%$ for HDL-C.

Abnormal lipid levels were defined using the following National Cholesterol Education Program (NCEP) guidelines ${ }^{27}$ : borderline TC, $170-199 \mathrm{mg} / \mathrm{dL}$ (4.58-5.15 mmol/ $\mathrm{L}^{28}$ ); high 
$\mathrm{TC}, \geq 200 \mathrm{mg} / \mathrm{dL}\left(5.17 \mathrm{mmol} / \mathrm{L}^{28}\right)$; borderline LDL-C, $110-129 \mathrm{mg} / \mathrm{dL}(2.84-3.34 \mathrm{mmol} /$ $\left.\mathrm{L}^{28}\right)$; high LDL-C, $\geq 130 \mathrm{mg} / \mathrm{dL}\left(3.3 \mathrm{mmol} / \mathrm{L}^{28}\right)$; and low HDL-C, $<35 \mathrm{mg} / \mathrm{dL}(0.9 \mathrm{mmol} /$ $\mathrm{L}^{28}$ ). Because the NCEP criteria do not include a definition for elevated, triglycerides a definition of $>110 \mathrm{mg} / \mathrm{dL}\left(1.24 \mathrm{mmol} / \mathrm{L}^{28}\right)$, which is based on the criteria of Cook and associates $^{29}$ and was developed from pediatric norms, was used in this study. Adoption of this criteria also allowed comparison with data from the 1999-2000 NHANES study. ${ }^{14}$

\section{Statistical Methods}

Because students with a previous diagnosis of diabetes were excluded from the study, we also excluded the 8 participants who possessed fasting glucose levels that were suggestive of type 2 diabetes (>126 mg/dL). Descriptive statistics, including means, standard deviations, and percents, were calculated for all variables. Separate generalized estimating equation (GEE) models that took into account clustering of observations within schools were used to analyze differences in the percent of students with elevated lipid and blood pressure values by categorical groupings (gender, BMI group, and Tanner stage). Equal correlation between all interschool observations (exchangeable) was chosen as the covariance structure. A multivariate approach was used to examine the possible interactions among gender, ethnic group, and BMI percentile in the prevalence of each of the risk factors. Models that included each of the main effects and the 2-way interactions were computed. However, because BMI percentile and ethnicity were highly correlated, this interaction was not included in the models, leaving only the gender*ethnicity and gender*BMI percentile interaction terms. All nonsignificant interaction terms were subsequently removed and the models rerun. Significant interactions were graphed. All $P$ values represent exploratory findings and are presented without adjustment for multiple comparisons with $\alpha$ set at .05. SAS 8.2 statistical software (SAS Institute Inc, Cary, $\mathrm{NC)}$ was used for all statistical analyses.

\section{RESULTS}

A total of 1740 eighth-grade students provided informed consent. An average of 144 (range: 85-199) students per school were recruited. The mean recruitment rate (participants/total number of available eighth-grade students) was $50 \%$ per school with a range of $33 \%$ to $67 \%$ per school. Comparing consented participants with previously established heights and weights of all students within the school indicated that participants in each school were representative with regard to the percent of students with BMI $\geq 85$ th percentile, percent by gender, and percent minority compared with the entire eighth-grade student population of each school. Table 1 presents descriptive statistics for the 1717 eighth-grade students for whom complete lipid and blood pressure data were obtained. Overall, the sample was $56 \%$ female, $50 \%$ Hispanic, $22 \%$ black, $14.3 \%$ white, and 2\% Native American. Ethnic distributions varied by site, with the Texas participants $69 \%$ Hispanic, $27 \%$ black, and $1 \%$ white, the California students $77 \%$ Hispanic, $13 \%$ white, and $2 \%$ black, and the North Carolina participants $48 \%$ black, $31 \%$ white, $4 \%$ Hispanic, and $8 \%$ Native American. All other participants described themselves as being of mixed heritage or other ethnic groups.

The students were $13.6 \pm 0.6$ years of age. There was little difference in self-reported Tanner stage with $81 \%$ of the boys reporting Tanner stage 3 or 4 and $92 \%$ of the girls reporting Tanner stage 4 or 5 . The rates of elevated blood pressure ranges from $12.8 \%$ of participants who were prehypertensive to $23.9 \%$ who had any HBP. The prevalence of elevated lipid levels ranged from $3.9 \%$ who had borderline LDL-C to $17.2 \%$ who had high triglyceride levels. Across the 3 sites, $19.8 \%$ of the participants (18.2\% Texas, $9.8 \%$ California, and $21.6 \%$ North Carolina) were at risk for overweight (BMI $\geq 85$ th percentile <95th percentile), whereas $29 \%$ (31.8\% Texas, $30.1 \%$ California, and $24.4 \%$ North Carolina) were overweight (BMI $\geq 95$ th percentile) based on the CDC age- and gender-specific percentiles. ${ }^{20}$ 
The percent of participants with elevated blood pressure and lipid values is shown in Table 2 . Boys were more likely to have elevated HBP than girls. Significantly more girls than boys had borderline TC, whereas significantly more boys than girls had low HDL-C cholesterol. There was a statistically significant difference in the percent of participants with low HDL-C among the ethnic groups with a lower prevalence among the black children than all other ethnic groups. There was a statistically significant difference in the percent of participants with high triglycerides among the ethnic groups with an increased prevalence among the Hispanics in comparison to all other ethnic groups.

Table 3 displays the percent of participants with elevated blood pressure and dyslipidemia for normal weight, at risk of overweight, and overweight participants. Among all students, and separately for both boys and girls, the percent who were prehypertensive, hypertensive, hypertensive, or had any HBP, low HDL-C, or high triglycerides increased with increasing BMI group. For all students and for boys only, the percent with borderline TC and borderline LDC-C increased with increasing BMI group. Among boys only, high TC increased with increasing BMI group.

There were no differences in the prevalence of lipid or blood pressure risk factors by pubertal development (as defined by Tanner stage) or level of parental education (data not shown). Among lipids, only the percent of students with high triglycerides increased with increasing blood pressure. The prevalence of high triglycerides was $14.7 \%$ among participants with normal blood pressure, $22.7 \%$ among prehypertensive participants, and $27.1 \%$ among hypertensive participants $(P=.001)$.

Table 4 shows the percent of participants with elevated blood pressure and lipid levels for both genders in each of the 4 largest ethnic groups. GEE regression models were used to predict elevated blood pressure and lipid levels while simultaneously adjusting for gender, BMI group, ethnic group, and relevant interaction terms. There were significant gender*ethnicity interactions in the percent with prehypertension $(P=.03)$ and any $\operatorname{HBP}(P=.02)$, indicating a higher prevalence of prehypertension and any HBP among white boys than girls (Fig 1). The prevalence of prehypertension and any HBP increased with BMI group $(P=.012$ and .009 , respectively). For any HBP only, boys had overall higher rates of BMI $(P=.009)$. For hypertension, the gender*ethnicity interaction approached significance $(P=.052)$, suggesting more hypertension among white boys than girls. In the same model, more boys than girls were hypertensive $(P=.009)$, and the prevalence of hypertension increased with BMI group $(P=$. 018).

There were no significant interactions in any models predicting elevated lipid levels. Gender $(P=.045)$ and BMI $(P=.032)$ predicted the percent of participants who had borderline high TC, whereas only BMI was a significant $(P=.011)$ independent predictor of borderline LDLC. Gender $(P=.007)$, BMI $(P=.018)$, and ethnicity $(P=.024)$ all independently predicted the percent of student with low HDL-C. BMI $(P=.014)$ and ethnicity $(P=.022)$ independently predicted the percent of students with high triglycerides.

\section{DISCUSSION}

In the NHANES 1999-2000 study, 8.0\% of participants had HBP (blood pressure >90th percentile for age, gender, and height), but much higher levels were found in this study for all participants regardless of ethnic subgroups. ${ }^{14}$ There was also a higher prevalence of elevated blood pressure in this study than in NHANES 1999-2000 across all the BMI groups. (A summary of the prevalence rates in NHANES 1999-2000 and this study is shown in Table 5.) Our higher prevalence was obtained using only eighth-grade participants, whereas the NHANES sample included 12- to 19-year-olds. The high prevalence of elevated blood pressure 
among this sample is concerning because HBP has been reported to track from childhood to adulthood, 5,6 and adult HBP has been associated with increased risk of stroke and cardiovascular disease. ${ }^{2}$

Contrary to research in adults that has shown higher hypertension rates among blacks, ${ }^{30,31}$ we found no ethnic differences in the prevalence of hypertension, prehypertension, or any HBP in this cohort. This is consistent with a recent study of hypertension among Houston, Texas, schools, which found no evidence of ethnic differences in the prevalence of hypertension among 5102 10- to 19 -year-old children after controlling for BMI. ${ }^{18}$ The higher prevalence of hypertension among our sample than in NHANES 1999-2000 is therefore, likely to be a function of greater number of participants in this study (29\% vs $15.5 \%$ ) who were overweight $\left(\mathrm{BMI}>95\right.$ th percentile). ${ }^{15}$

The prevalence of high triglycerides was lower in this sample (17.2\%) than in NHANES 1999-2000 (23.2\%) for all participants and all gender, ethnic, and BMI subgroups using the same cut point $(\geq 110 \mathrm{mg} / \mathrm{dL}) .{ }^{14}$ The prevalence of high TC (4.0\%) and high LDL-C (3.9\%) was lower in our sample than in the Bogalusa sample from 1984-1994, in which prevalence rates of $9 \%$ and $8 \%$ were reported using the same cut points. ${ }^{13}$ The lower prevalences of high triglycerides and TC in this study could be a function of the limited age of participants in this study (all eighth grade) compared with the 11- to 17- and 12- to 19-year-old ranges used in the Bogalusa and NHANES 1999-2000 studies. Given the advanced Tanner stage of the study participants and the known reductions in LDL-C that occur with puberty, ${ }^{32}$ the lower prevalence found in this study could be a function of participants pubertal stage.

More boys than girls in this cohort were categorized as hypertensive. There was also a genderby-ethnicity interaction in the prevalence of hypertension and any HBP with a higher prevalence of both prehypertension and any HBP among white boys than girls. These findings are consistent with previous reports ${ }^{18}$ and suggest that there is a need to focus on reducing HBP among early male adolescents. Similar to NHANES 1999-2000, there was an increased prevalence of low HDL-C among the boys in this sample. ${ }^{14}$ More girls than boys had borderline $\mathrm{TC}$, which is consistent with previous research that has reported higher TC levels among girls. 33 The implication of these findings is that gender-specific strategies to reduce the TC of girls and increase the HDL-C levels of boys may aid the prevention of cardiovascular diseases.

The lower prevalence of HDL-C levels among black children in this study is similar to the findings of NHANES 1999-2000, which also reported a lower prevalence of low HDL-C among black children. ${ }^{14}$ We found an increased prevalence of high triglycerides among the Hispanic participants, which is also similar to the findings of NHANES 1999-2000. ${ }^{14}$ These findings suggest that there is a need to develop specific strategies to decrease triglyceride levels of Hispanics.

The association between higher BMI and increased lipid and blood pressure levels suggest that lipid screenings should be recommended for all children and adolescents with BMI > 85th percentile for age and gender. Although regular blood pressure screenings are common, current NCEP guidelines call for the screening of all children and adolescents with a family history of elevated lipid levels, atherosclerosis, or other cardiovascular illnesses as well as those children with other risk factors. ${ }^{27}$ Because increases in blood pressure were associated with elevated triglyceride levels, the results of this study suggest that lipid screenings should be recommended for all participants who are either at risk for overweight or with elevated blood pressure levels.

Although lipid ${ }^{8,11}$ and blood pressure levels ${ }^{11,12}$ have previously been shown to vary by developmental stage, we detected no such relationships in this study. Because $92 \%$ of the girls were categorized as either Tanner stage 4 or 5 and most of the boys categorized as Tanner stage 
3 or 4 , this is likely a function of the lack of variability within the sample. Additional research that includes a wider distribution of pubertal groups is required to examine the association between developmental stage and the prevalence of cardiovascular risk factors.

The prevalence of elevated blood pressure and lipid levels did not differ by parental educational attainment in this sample. This is contrast to previous studies that have reported differences in the lipid and blood pressure levels of children from high or low socioeconomic schools. ${ }^{33}$

Because schools were required to have at least $50 \%$ of their students eligible for free or reducedprice lunch to participate in the study, this is likely a function of study design. Additional research that includes greater distribution of parental education is required to fully examine whether the prevalence of cardiovascular risk factors differs by socioeconomic status in a diverse group of adolescents.

\section{Strengths and Limitations}

The major strength of this study is the large, ethnically diverse sample that was obtained from 3 distinct geographic regions within America during the current obesity epidemic. This has enabled us to report the prevalence of risk factors and compare our findings with those of previous studies. The sample is, however, limited by a small age range and the lack of variability in the pubertal development of the participants, which prevented us from fully exploring the relationship between pubertal development and prevalence of risk factors. Because diabetics (either type 1 or type 2) were excluded from the study and the analyses, it is possible that the prevalence of elevated lipid levels could be underestimated. Furthermore, although this sample was purposely selected to provide information about risk among adolescents from low-income homes, this restricted our ability to assess changes in the prevalence of risk and was limited by a lack of diversity in socioeconomic status. It is also important to acknowledge that we did not assess the participants' diet, ${ }^{34,35}$ habitual physical activity level, ${ }^{36}$ or tobacco use ${ }^{37}$ in this study, which could be important because all 3 factors have been associated with increased prevalence of cardiovascular risk factors in adolescents.

\section{CONCLUSIONS}

The data presented here show that the prevalence of hypertension among this sample of minority adolescents was greater than previous national surveys, with this increase likely a function of the increased levels of overweight among this sample. Curbing the pediatric obesity epidemic is necessary to reduce the disease risk of US adolescents, and lipid and blood pressures screenings should be considered for youths at risk for overweight.

\section{ACKNOWLEDGMENTS}

This work was completed with funding from National Institute of Diabetes and Digestive and Kidney Diseases/ National Institutes of Health grants U01-DK61230 (George Washington University), U01-DK61249 (University of California, Irvine), U01-DK61231 (Baylor College of Medicine), and U01-DK61223 (University of North Carolina at Chapel Hill). The following individuals and institutions contributed to the reported results as members of the STOPPT2D Prevention Study Group (*members of the writing group): Field Center (Baylor College of Medicine): T. Baranowski, PhD, J. Baranowski, MS, RD, LD, A. Canada, K. Cullen, DrPH, RD, LD, *R. Jago, PhD, M. Missaghian, MS, MPH, D. Thompson, PhD, V. Thompson, DrPH, and B. Walker, RN; Field Center (University of California, Irvine): D. M. Cooper, MD, *S. Bassin, EdD, K. Blackler, F. Culler, MD, D. Ford, and P. Galassetti, MD, PhD; Field Center (University of North Carolina at Chapel Hill): *J. Harrell, PhD, RN, *R. G. McMurray, PhD, J. Buse, MD, T. Hackney, PhD, D. Rubin, PhD, M. A. Morris, MD, and K. Kirby; Coordinating Center (George Washington University): K. Hirst, PhD, *S. Edelstein, ScM, *L. El Ghormli, MSc, S. Grau, MA, and L. Pyle, MS; Program Office (National Institute of Diabetes and Digestive and Kidney Diseases): B. Linder, MD, PhD; Central Blood Laboratory (Northwest Research Lipid Laboratories): S. Marcovina, PhD, ScD. STOPP-T2D Study Chair: F. R. Kaufman, MD (Childrens Hospital Los Angeles); other study group members: M. Goran, PhD (University of Southern California), and K. Resnicow, PhD (University of Michigan). 


\section{Abbreviations}

LDL-C, low-density lipoprotein cholesterol; HDL-C, high-density lipoprotein cholesterol; NHANES, National Health and Nutrition Examination Survey; CDC, Centers for Disease Control and Prevention; PDS, Pubertal Development Scale; HBP, high blood pressure; TC, total cholesterol; NCEP, National Cholesterol Education Program; GEE, generalized estimating equation.

\section{REFERENCES}

1. Tracy RE, Newman WP, Wattigney WA, Berenson GS. Risk factors and atherosclerosis in youth autopsy findings of the Bogalusa Heart Study. Am J Med Sci 1995;310:S37-S41. [PubMed: 7503122]

2. Mahoney LT, Lauer RM, Lee J, Clarke WR. Factors affecting tracking of coronary heart disease risk factors in children. The Muscatine Study. Ann N Y Acad Sci 1991;623:120-132. [PubMed: 2042820]

3. Webber LS, Srinivasan SR, Wattingney WA, Berenson GS. Tracking of serum lipids and lipoproteins from childhood to adulthood: The Bogalusa Heart Study. Am J Epidemiol 1991;133:884-849. [PubMed: 2028978]

4. Nicklas TA, von Duvillard SP, Berenson GS. Tracking of serum lipids and lipoproteins from childhood to dyslipidemia in adults: The Bogalusa Heart Study. Int J Sports Med 2002;23(suppl):s39-s43. [PubMed: 12012261]

5. Bao W, Threefoot SA, Srinivasan SR, Berenson GS. Essential hypertension predicted by tracking of elevated blood pressure from childhood to adulthood: the Bogalusa Heart Study. Am J Hypertens 1995;8:657-665. [PubMed: 7546488]

6. Fuentes RM, Notkola IL, Shemeikka S, Tuomilehto J, Nissinen A. Tracking of systolic blood pressure during childhood: a 15 year follow-up population-based family study in eastern Finland. J Hypertens 2002;20:195-202. [PubMed: 11821703]

7. Hickman TB, Briefel RR, Carrol MD, et al. Distributions and trends of serum lipid levels among United States children and adolescents aged 4-19 years: data from the Third National Health and Nutrition Examination Survey. Prev Med 1998;27:879-890. [PubMed: 9922071]

8. Bertrais S, Balkau B, Charles MA, et al. Puberty-associated differences in total cholesterol and triglyceride levels according to sex in French children aged 10-13 years. Ann Epidemiol 2000;10:316323. [PubMed: 10942880]

9. Muntner P, He J, Cutler JA, Wildman RP, Whelton PK. Trends in blood pressure among children and adolescents. JAMA 2004;291:2107-2113. [PubMed: 15126439]

10. Winkleby MA, Robinson TN, Sundquist J, Kraemer HC. Ethnic variation in cardiovascular disease risk factors among children and young adults: findings from the Third National Health and Nutrition Examination Survey, 1988-1994. JAMA 1999;281:1006-1013. [PubMed: 10086435]

11. Tell GS. Cardiovascular disease risk factors related to sexual maturation: the Oslo Youth Study. J Chronic Dis 1985;38:633-642. [PubMed: 4019701]

12. Weir MR, Stafford EM, Gregory G, Lawson MA, Pearl W. The relationship between sexual maturity rating, age and increased blood pressure in adolescents. J Adolesc Health Care 1988;9:465-469. [PubMed: 3182359]

13. Freedman DS, Dietz WH, Srinivasan SR, Berenson GS. The relation of overweight to cardiovascular risk factors among children and adolescents: the Bogalusa Heart Study. Pediatrics 1999;103:11751182. [PubMed: 10353925]

14. Duncan GE, Li SM, Zhou XH. Prevalence and trends of a metabolic syndrome phenotype among US adolescents, 1999-2000. Diabetes Care 2004;27:2438-2443. [PubMed: 15451913]

15. Ogden CL, Flegal KM, Carroll MD, Johnson CL. Prevalence and trends in overweight among US children and adolescents, 1999-2000. JAMA 2002;288:1728-1732. [PubMed: 12365956]

16. Simon JA, Morrison JA, Similo S, McMahon RP, Schreiber GB. Correlates of high-density lipoprotein cholesterol in black girls and white girls: the NHLBI growth and health study. Am J Public Health 1995;85:1698-1702. [PubMed: 7503349]

17. Resnicow K, Futterman R, Vaughan RD. Body mass index as a predictor of systolic blood pressure in a multiracial sample of US schoolchildren. Ethn Dis 1993;3:351-361. [PubMed: 7888986] 
18. Sorof JM, Lai D, Turner J, Poffenbarger T, Portman RJ. Overweight, ethnicity, and the prevalence of hypertension in school-aged children. Pediatrics 2004;113:475-482. [PubMed: 14993537]

19. Hedley AA, Ogden CL, Johnson CL, Carroll MD, Curtin LR, Flegal KM. Prevalence of overweight and obesity among US children, adolescents, and adults, 1999-2002. JAMA 2004;291:2847-2850. [PubMed: 15199035]

20. National Center for Health Statistics. 2000 CDC growth charts: United States. Available at: www.cdc.gov/growthchartsAccessed April 15, 2003

21. Petersen AC, Crockett L, Richards M, Boxer A. A self-report measure of pubertal status: Reliability, validity, and initial norms. Youth Adolesc 1988;17:117-133.

22. National High Blood Pressure Education Program Working Group on High Blood Pressure in Children and Adolescents. The fourth report on the diagnosis, evaluation, and treatment of high blood pressure in children and adolescents. Pediatrics 2004;114:555-576. [PubMed: 15286277]

23. Warnick GR. Enzymatic methods for quantification of lipoprotein lipids. Methods Enzymol 1986;129:101-123. [PubMed: 3724535]

24. Fridewald WT, Levy RI, Fredrickson DS. Estimation of the concentration of low-density lipoprotein cholesterol in plasma, without use of the preparative ultracentrifuge. Clin Chem 1972;18:499-502. [PubMed: 4337382]

25. Warnick GR, Knopp RH, Fitzpatrick V, Branson L. Estimating low-density lipoprotein cholesterol by the Fridewald equation is adequate for classifying patients on the basis of nationally recommended cutpoints. Clin Chem 1990;36:15-19. [PubMed: 2297909]

26. Hainline, AJ.; Karon, J.; Kippel, K. Manual of Laboratory Operations: Lipid Research Clinics Program, Lipid and Lipoprotein Analysis. Vol. 2nd ed. US Department of Health and Human Services; Washington, DC: 1983.

27. National Cholesterol Education Program (NCEP). Highlights of the report of the expert panel on blood cholesterol in children and adolescents. Pediatrics 1992;89:495-501. [PubMed: 1741227]

28. Young DS. Implementation of SI units for clinical laboratory data. Style specifications and conversion tables. Ann Intern Med 1987;106:114-129. [PubMed: 3789557]

29. Cook S, Weitzman M, Auinger P, Nguyen M, Dietz WH. Prevalence of a metabolic syndrome phenotype in adolescents: findings from the third National Health and Nutrition Examination Survey, 1988-1994. Arch Pediatr Adolesc Med 2003;157:821-827. [PubMed: 12912790]

30. Frisancho AR, Leonard WR, Bollettino LA. Blood pressure in blacks and whites and its relationship to dietary sodium and potassium intake. J Chronic Dis 1984;37:515-519. [PubMed: 6746843]

31. Nelson TL, Hunt KJ, Rosamond WD, et al. Obesity and associated coronary heart disease risk factors in a population of low income African-American and white women: the North Carolina WISEWOMAN project. Prev Med 2002;35:1-6. [PubMed: 12079434]

32. Kwiterovich PO Jr, Barton BA, McMahon RP, et al. Effects of diet and sexual maturation on lowdensity lipoprotein cholesterol during puberty: the Dietary Intervention Study in Children (DISC). Circulation 1997;96:2526-2533. [PubMed: 9355889]

33. Resnicow K, Morley-Kotchen J, Wynder E. Plasma cholesterol levels of 6585 children in the United States: results of the know your body screening in five states. Pediatrics 1989;84:969-976. [PubMed: 2587152]

34. Nicklas TA, Dwyer J, Feldman HA, Luepker RV, Kelder SH, Nader PR. Serum cholesterol levels in children are associated with dietary fat and fatty acid intake. J Am Diet Assoc 2002;102:511-517. [PubMed: 11985407]

35. Nicklas TA, Farris RP, Smoak CG, et al. Dietary factors relate to cardiovascular risk factors in early life. Bogalusa Heart Study. Arteriosclerosis 1988;8:193-199. [PubMed: 3348759]

36. Raitakari OT, Taimela S, Porkka KV, et al. Associations between physical activity and risk factors for coronary heart disease: the Cardiovascular risk in Young Finns Study. Med Sci Sports Exerc 1997;29:1055-1061. [PubMed: 9268963]

37. Craig WY, Palomaki GE, Johnson AM, Haddow JE. Cigarette smoking-associated changes in blood lipid and lipoprotein levels in the 8- to 19-year-old age group: a meta-analysis. Pediatrics 1990;85:155-158. [PubMed: 2136949] 


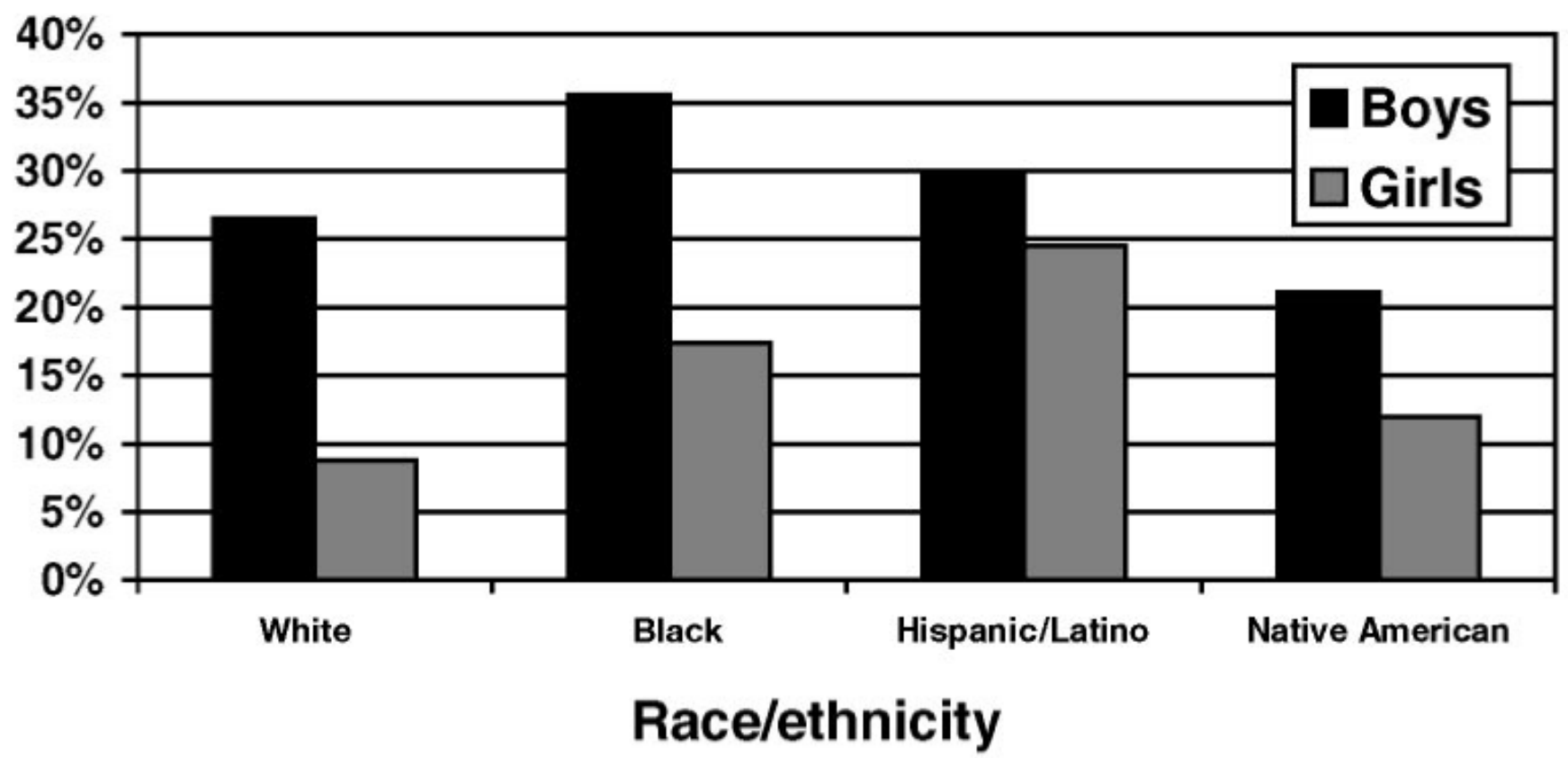

FIGURE 1.

Prevalence of HBP (either systolic or diastolic blood pressure $\geq 90$ th percentile) by ethnicity and gender indicating significant gender differences for white children. 


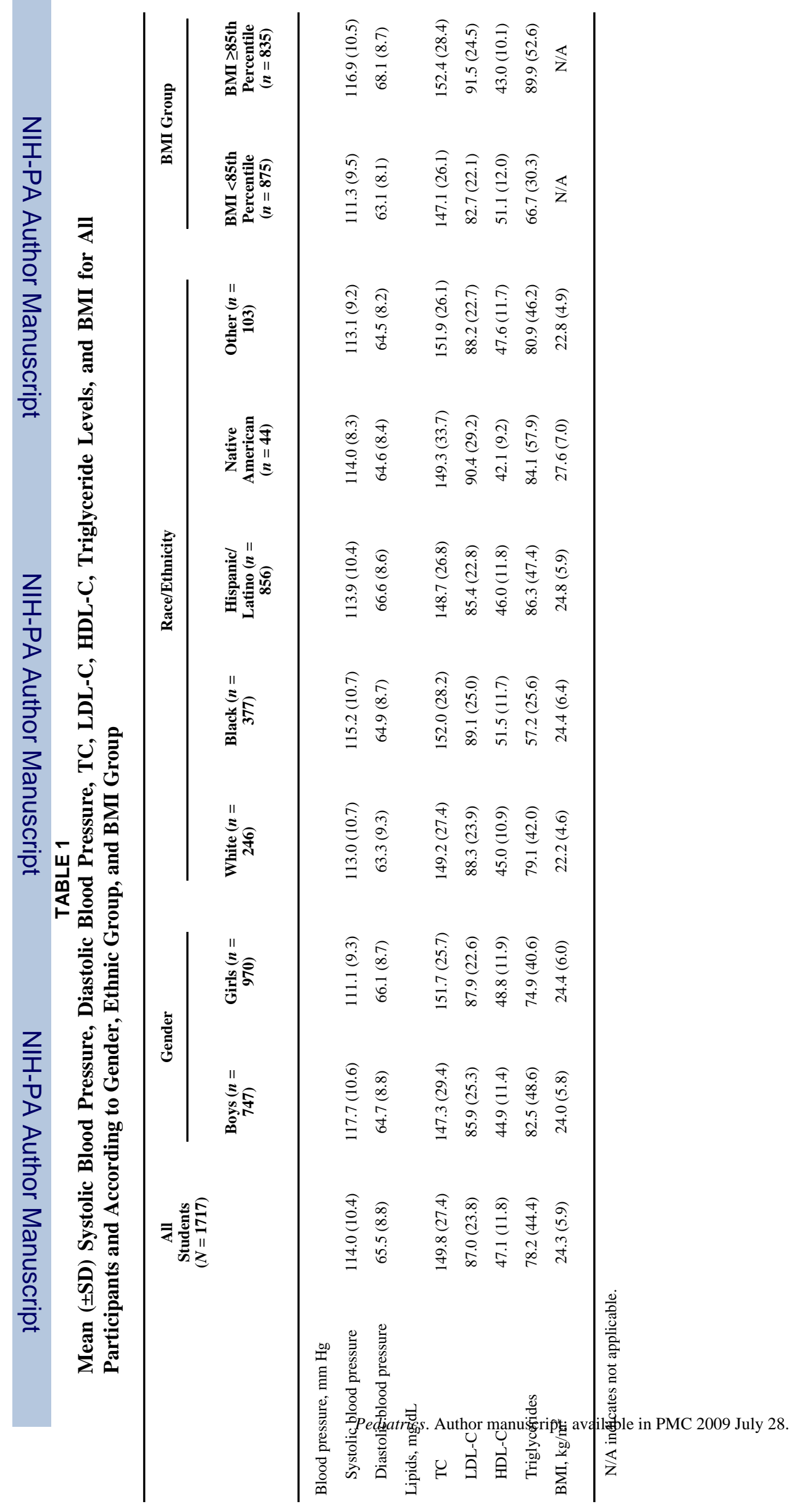




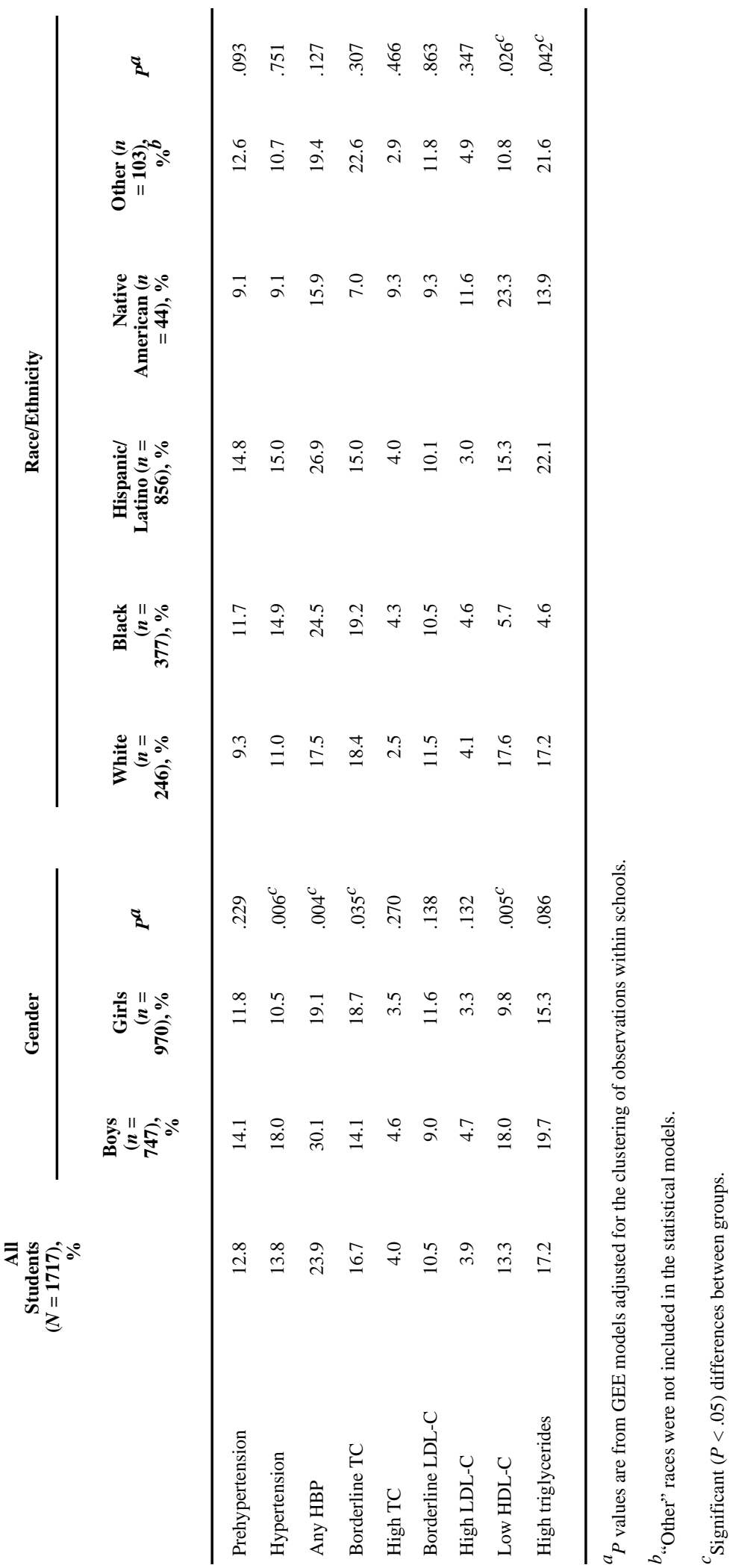




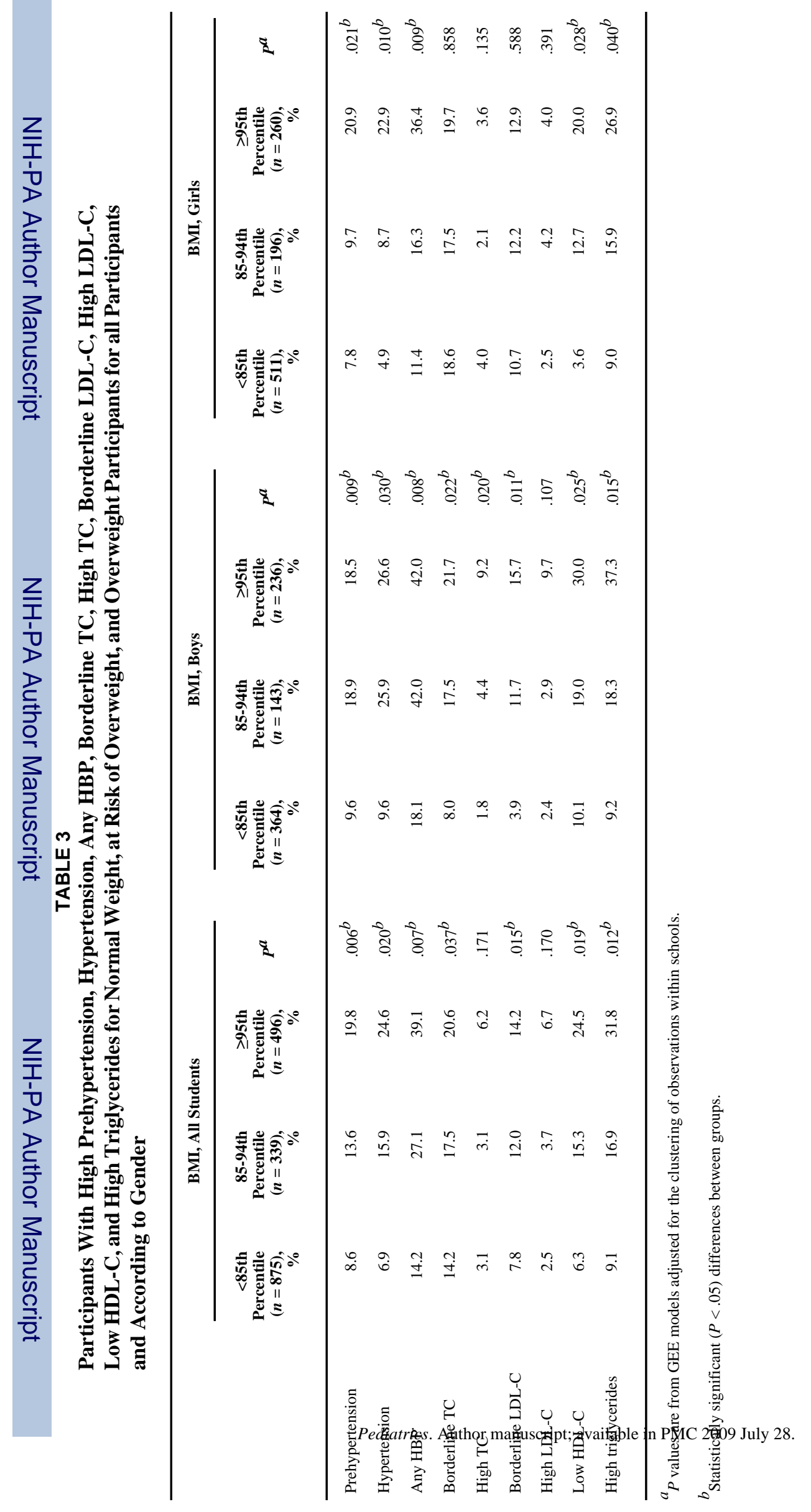




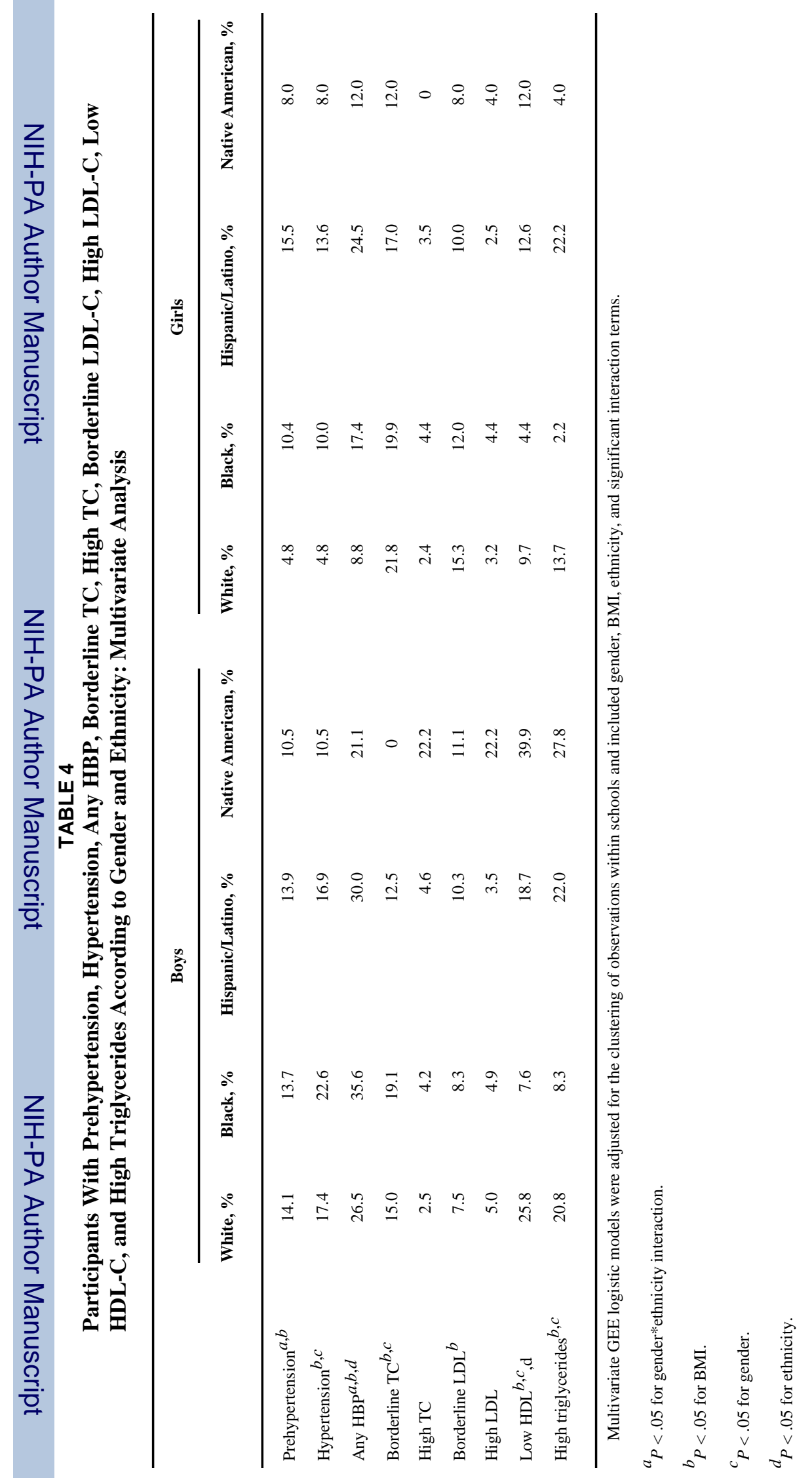

Pediatrics. Author manuscript; available in PMC 2009 July 28. 
TABLE 5

Prevalence of Any HBP in This Study and NHANES 1999-2000 for All Participants and for Ethnic and BMI Subgroups

\begin{tabular}{lcr}
\hline & This Study, $\boldsymbol{a}^{\boldsymbol{a}}$ & NHANES 1999-2000, $\boldsymbol{b}$ \\
\hline All participants & 23.9 & 8.0 \\
Race/ethnicity & 17.5 & 7.5 \\
White & 24.5 & 12.7 \\
Black & 26.9 & 11.3 \\
Hispanic & & 4.4 \\
BMI group & 14.2 & 6.0 \\
Normal weight (BMI $<85$ th percentile) & 27.1 & 25.6 \\
At risk for overweight (BMI $\geq 85$ th to $<95$ th & & \\
percentile) & 39.1 & \\
Overweight (BMI $\geq 95$ th percentile) & & \\
\hline
\end{tabular}

“Any HBP" includes either diastolic blood pressure or systolic blood pressure >90th percentile for age, gender, and height.

${ }^{a}$ Eighth-grade participants only.

${ }^{b}$ Participants 12 to 19 years of age. 